\title{
Risk of hyperkalemia in patients with moderate chronic kidney disease initiating angiotensin converting enzyme inhibitors or angiotensin receptor blockers: a randomized study
}

Eugenia Espinel ${ }^{1 *}$, Jorge Joven ${ }^{2}$, Iván Gill ${ }^{1}$, Pilar Suñé $^{3}$, Berta Renedo $^{3}$, Joan Fort $^{1}$ and Daniel Serón ${ }^{1}$

\begin{abstract}
Background: Angiotensin-converting enzyme inhibitors and angiotensin II receptor blockers are renoprotective but both may increase serum potassium concentrations in patients with chronic kidney disease (CKD). The proportion of affected patients, the optimum follow-up period and whether there are differences between drugs in the development of this complication remain to be ascertained.

Methods: In a randomized, double-blind, phase IV, controlled, crossover study we recruited 30 patients with stage 3 CKD under restrictive eligibility criteria and strict dietary control. With the exception of withdrawals, each patient was treated with olmesartan and enalapril separately for 3 months each, with a 1-week wash-out period between treatments. Patients were clinically assessed on 10 occasions via measurements of serum and urine samples. We used the Cochran-Mantel-Haenszel statistics for comparison of categorical data between groups. Comparisons were also made using independent two-sample $t$-tests and Welch's $t$-test. Analysis of variance (ANOVA) was performed when necessary. We used either a Mann-Whitney or Kruskal-Wallis test if the distribution was not normal or the variance not homogeneous.

Results: Enalapril and olmesartan increased serum potassium levels similarly $(0.3 \mathrm{mmol} / \mathrm{L}$ and $0.24 \mathrm{mmol} / \mathrm{L}$ respectively). The percentage of patients presenting hyperkalemia higher than $5 \mathrm{mmol} / \mathrm{L}$ did not differ between treatments: $37 \%$ for olmesartan and $40 \%$ for enalapril. The mean e-GFR ranged 46.3 to $48.59 \mathrm{ml} / \mathrm{mint} / 1.73 \mathrm{~m}^{2}$ in those treated with olmesartan and 46.8 to $48.3 \mathrm{ml} / \mathrm{mint} / 1.73 \mathrm{~m}^{2}$ in those with enalapril and remained unchanged at the end of the study. The decreases in microalbuminuria were also similar (23\% in olmesartan and 29\% in enalapril patients) in the 4 weeks time point. The percentage of patients presenting hyperkalemia, even after a two month period, did not differ between treatments. There were no appreciable changes in sodium and potassium urinary excretion.
\end{abstract}

Conclusions: Disturbances in potassium balance upon treatment with either olmesartan or enalapril are frequent and without differences between groups. The follow-up of these patients should include control of potassium levels, at least after the first week and the first and second month after initiating treatment.

Trial registration: The trial EudraCT "2008-002191-98".

\footnotetext{
*Correspondence: 13047eeg@comb.cat

'Servei de Nefrologia, Hospital Vall d'Hebron, Universitat Autònoma,

Barcelona, Spain

Full list of author information is available at the end of the article
} 


\section{Background}

The rate of raised serum potassium concentration in hospitalized patients and in admissions to emergency departments is high and may represent an ominous marker of increased risk of death [1]. This is more common among patients with impaired renal function and defects in the excretion of renal potassium, with some associated clinical conditions and treatment with a growing list of drugs [2-7]. Although there is considerable inter-individual variation in susceptibility, hyperkalemia may be responsible for alterations in the excitatory capacity of the heart conduction system and is consequently associated with severe arrhythmogenesis and fatal consequences $[8,9]$.

The incidence of hyperkalemia is quite low in patients with normal renal function: $>2 \%$ but increases from $2 \%$ to $42 \%$ as the GFR diminishes to $20 \mathrm{ml} / \mathrm{min} 1.73 / \mathrm{m}^{2}$ [10]. There are multiple triggering factors in chronic kidney disease (CKD) patients, but a significant proportion of episodes of hyperkalemia are attributed to the use of drugs taken to alleviate concomitant hypertension, especially angiotensin-converting enzyme inhibitors (ACEIs) and angiotensin receptor blockers (ARBs) as they inhibit the renin-angiotensin system and cause a reduction in serum aldosterone [11]. It has been also described that hyperkalemia develops in approximately 10 percent of outpatients within a year of ACEIs being prescribed [12]. Furthermore, in six separate clinical trials of more than 1500 people with CKD, increased levels of 0.3-0.6 mmol/L were detected in the ACEI randomized patients [7]. This increase in serum potassium led to discontinuation of ACEI therapy in 1.2 to $1.6 \%$ of patients in any given trial.

Both ACEIs and ARBs are widely included in clinical guidelines to manage hypertension and other risk factors associated with the course of atherosclerosis [13-15] and may significantly delay the progression of renal damage in patients with chronic kidney disease [16-21]. Therefore, nephrologists face a paradoxical and clinically significant challenge in this realm because those patients who would benefit most from treatment with ACEIs or ARBs are precisely those with the highest risk of adverse effects. In addition, in these patients any prediction of potentially dangerous potassium disturbances is complicated by the consequences of a non-controlled diet, concomitant drugs and other associated chronic diseases. Consequently, safety issues regarding the use of these drugs in patients with renal insufficiency and in those with moderate CKD are not yet completely established $[22,23]$. The real incidence of hyperkalemia as a result of these treatment regimes is not well known because available evidence is difficult to interpret due to the influence of confounding factors [24-26], which is particularly evident in patients with CKD [27]. Despite the lack of clear evidence some authors have stated that the increase in serum potassium is less pronounced during therapy with
ARBs and that the risk of hyperkalemia is higher in patients treated with ACEIs [7,23].

Data supporting potential differences between ACE inhibitors and ARBs in serum potassium concentrations come from clinical trials that compare the effect of an ACEI to an ARB on renal function in people with heart failure. These trials demonstrated a lower incidence of hyperkalemia in patients randomly assigned to an ARB treatment compared with those randomized to ACEI treatment. In these studies there was a similar proportion of patients with CKD but they were receiving, at the same time, not only other different potassium-influencing drugs (diuretics, betablockers or potassium supplements) [24,28], but at different and non-specified doses.

We believe to demonstrate that one drug or another produces more or less hyperkalemia it is indispensable that this be the only potassium-influencing medication utilized. So currently there is little clear evidence for assuming differences between equipotent doses of ARB and ACEI to cause hyperkalemia.

Hence, our study is designed in this way, so that the only potassium-influencing drugs which our patients received were those permitted in the trial. All our patients had the same level of CKD and they followed a standardized potassium diet.

Bearing in mind the large amount of patients indicated to receive ACEIs or ARBs, the risk of associated CKD (heart failure, advanced age, etc.), as well as the risk of hyperkalemia, we believed that it would be of great interest to learn whether one of these medications produce less hyperkalemia than the other.

In this study we challenge this assumption by assessing the effect of standard-of-care treatment with olmesartan and enalapril, as representatives of ARBs and ACEIs respectively, on the incidence of hyperkalemia in patients with stage 3 CKD.

\section{Methods}

It was designed as a randomized, double-blind, phase IV, controlled, crossover study.

Among patients attending our outpatient clinic for management of CKD in a tertiary care teaching hospital, patients with stage $3 \mathrm{CKD}$, i.e. estimated GFR (eGFR) between 30 and $60 \mathrm{ml} / \mathrm{min} / 1.73 \mathrm{~m}^{2}$, stable clinical condition, aged 18-75 years, serum potassium concentration $<5 \mathrm{mmol} / \mathrm{L}$ and blood pressure (BP) ranging between $130 / 80 \mathrm{mmHg}$ and $180 / 100 \mathrm{mmHg}$, were considered for inclusion $(n=120)$. The use of calcium channel blockers or alpha-adrenergic blockers was not an exclusion criterion. For enrollment, strict exclusion criteria were established to exclude the presence of confounding factors that could alter the incidence of potassium disturbances during the treatment period as outlined in Table 1 . No patient with a known arterial 
Table 1 Criteria for exclusion reported during the enrollment period

\begin{tabular}{llll}
\hline Declined to participate & $(n=26)$ & Secondary arterial hypertension & $(n=5)$ \\
Previous allergic reaction to ACEls & $(n=3)$ & Previous allergic reaction to ARBs & $(n=2)$ \\
Active disease in other organs & $(n=6)$ & Previous gastrointestinal surgery & Recent (1 year) ischemic episodes \\
Diseases causing malabsorption & $(n=1)$ & History of cardiac insufficiency & $(n=1)$ \\
History of ventricular arrhythmias & $(n=2)$ & Current prescription with potassium & $(n=8)$ \\
Current prescription with diuretics & $(n=9)$ & Current prescription with NSAIDs & $(n=4)$ \\
Current prescription with B-blockers & $(n=7)$ & $(n=3)$
\end{tabular}

ACEIs: Angiotensin-converting enzyme inhibitors, ARBs: Angiotensin receptor blockers, NSAIDs: nonsteroidal anti-inflammatory drugs, B-blockers: Beta-blockers.

renal stenosis was included. The attending physicians identified 34 eligible patients, 4 of whom were discarded during the screening visits due to failure to follow a balanced diet that was relatively low in sodium and contained $80-90 \mathrm{mmol} /$ day of potassium as assessed via repeated measurement of electrolytes in 24-h urine samples. To fulfill restrictive eligibility criteria and strict dietary control patients were also instructed not to ingest salt substitutes or herbs. Finally we recruited 30 patients with stage 3 CKD who were informed about the trial and invited to participate and sign the informed consent approved by our institutional review board. Patients received olmesartan and enalapril sequentially, (Figure 1) and we chose the two-period design for simplicity. Raised serum potassium levels and lack of adherence were defined as reasons for withdrawal.

This number was considered sufficient according to available data [23] and assuming a difference between groups exceeding $10 \%$, an overall standard deviation of $20 \%$ and $80 \%$ power with a two-sided $5 \%$ significance level. We anticipated that dropouts and withdrawals would not influence the primary outcome, i.e. the proportion of patients in whom hyperkalemia was detected. We then proceeded according to Figure 1. Enrolled patients (20 men and 10 women) were born in our geographic area and all of them were Caucasian. There were no differences in age, BMI or other relevant variables (Table 2). Thus patients received olmesartan and enalapril sequentially in a controlled crossover, longitudinal design (Figure 1). We considered hyperkalemia as potassium level of $5.0 \mathrm{mmol} / \mathrm{L}$ or higher $[10,29]$.

We withdrew ACEIs, ARABs, betablockers, diuretics and any drug which could influence potassium levels 15 days before performing the baseline analyses. After that we randomized the patients to receive either: $10 \mathrm{mg}$ of olmesartan or $10 \mathrm{mg}$ of enalapril for one week, after which we performed an analytic determination. At that point patients with potassium levels $<5 \mathrm{mmol} / \mathrm{L}$ were instructed to increase the dose to $20 \mathrm{mg}$ /day in week 3, with an analytic control at week 4 . Following, that controls were performed at weeks 8 and 12. Once this phase was finished and after a 7-10 day wash-out period, the patients were prescribed the alternative drug and repeated this itinerary for three months more. Any patient with potassium $>5 \mathrm{mmol} / \mathrm{L}$ was withdrawn from the trial. Those patients withdrawn from the first phase underwent a 7-10 day wash-out period and, after ensuring their potassium levels were normal, were then transferred to the second phase.

Each patient was visited 10 times throughout the study for reinforcement and to avoid severe complications. Health care providers and participants were blinded to the drug assignment. The members of staff responsible for the intervention were instructed to temporarily stop the medication if hyperkalemia, changes in renal function or lack of adherence to the diet were detected. This was achieved with the independent contribution of pharmacists who were also responsible for dispensing the drugs in numbered bottles to conceal the allocation sequence, simple randomization using a computerized random number generator and storage of the allocation list. These procedures resulted in unbalanced allocation $(\mathrm{n}=17$ for olmesartan and $n=13$ for enalapril). After the wash-out period at the crossover stage, some patients refused to continue the study, alleging the requirement for excessive commitment. Secondary measurement outcomes included potentially affected variables. Blood pressure and eGFR were measured as described elsewhere [13,30]. Adherence to medication and diet was assessed using the Morisky-Green test and the brief medication questionnaire [31,32]. Whilst no data is available comparing equipotent doses of olmesartan (half life 12 hours) with enalapril (half life 11 hours), there are other studies comparing $5 \mathrm{mg}$ of ramipril with $20 \mathrm{mg}$ of enalapril or $5 \mathrm{mg}$ of ramipril with $20 \mathrm{mg}$ de olmesartan, meaning that these doses of enalapril and olmesartan could be considered comparable [33,34].

Routine analyses at each visit included creatinine, potassium, sodium and osmolarity in serum and albumin (microalbuminuria), creatinine, sodium and potassium in urine. At the beginning and the end of two periods of treatment (visits 1, 5, 6 and 10), plasma renin activity and aldosterone were also measured. The trial was according to the Helsinki declaration and was authorized by the local ethics committee and by the Spanish Agency for Medicines and Medical Products (AGEMED) which provided support and authorized the trial EudraCT “2008-002191-98”. 


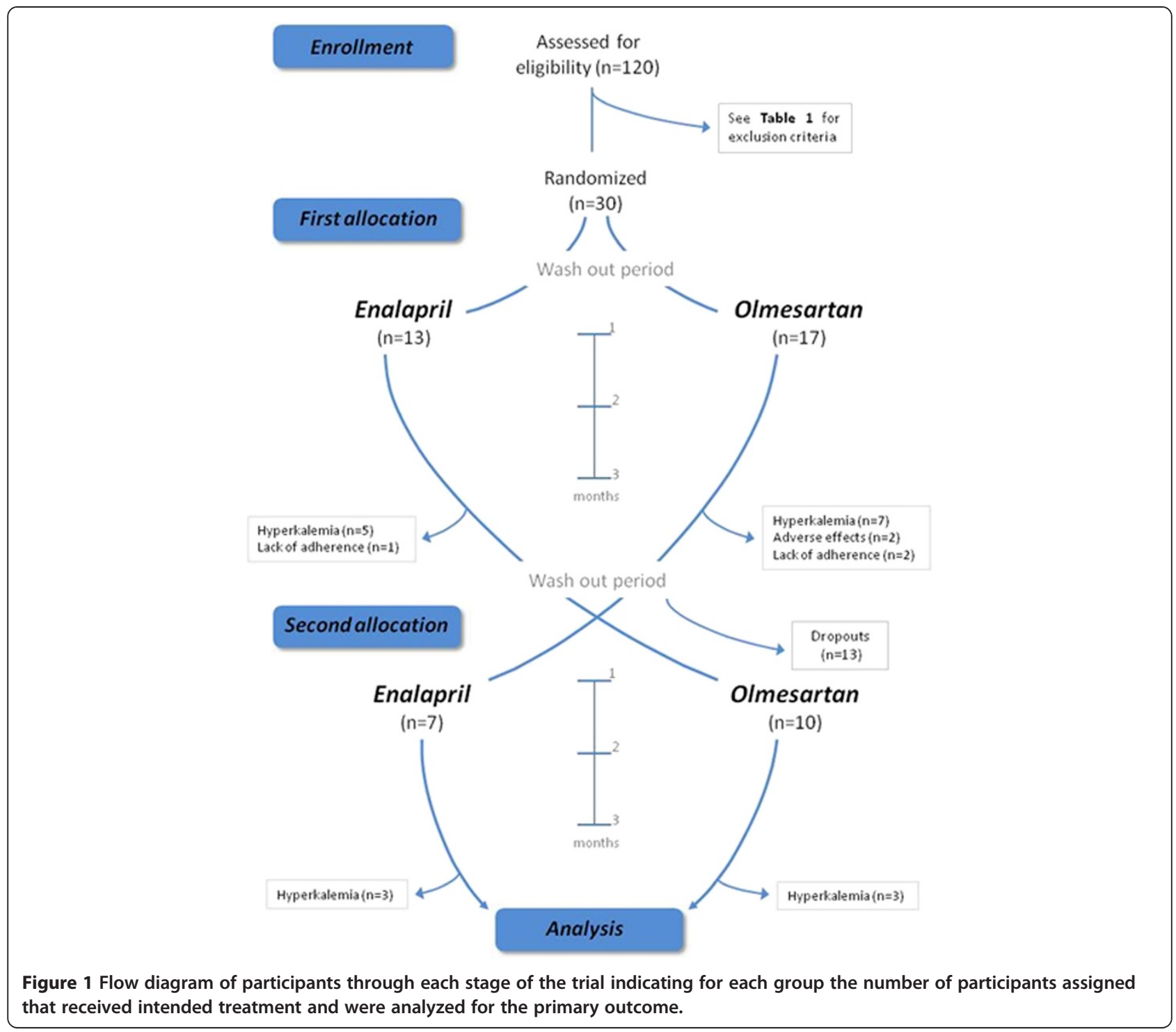

All analyses were performed according to standard procedures using automatic analyzers. Allocation concealment was extended to the laboratory personnel. Unless otherwise stated, variables are expressed as mean and standard error of the mean. We used the CochranMantel-Haenszel statistics for comparison of categorical data between groups, particularly the proportion of patients with hyperkalemia. Comparisons were also made using independent two-sample $t$-tests, in some cases with unequal sample sizes and unequal variance (Welch's $t$-test). To avoid multiple two-sample t-tests and the increased chance of committing a type I error, analysis of variance (ANOVA) was performed when necessary. We used either a Mann-Whitney or Kruskal-Wallis test if the distribution was not normal or the variance was not homogeneous. A two-tailed $\mathrm{P}<0.05$ was considered statistically significant. Individual missing data were not imputed in an expectation-maximization algorithm. Statistical analyses were performed using the Statistical Package for the Social Sciences, version 18.0 (SPSS Inc., Chicago, Il, USA).

\section{Results}

During the first period, $38 \%$ of patients receiving enalapril developed hyperkalemia, all during the first week. Hyperkalemia in the olmesartan group was detected in $41 \%$ of patients at different time-points (weeks $1(n=3), 4$ $(\mathrm{n}=3)$ and $8(\mathrm{n}=1))$. At the end of the first period, 13 patients declined to continue for various reasons, confirming the high rate of attrition in studies with designs that require strong commitment, continuous control of diet and other confounding factors. We considered that 7-10 days of wash out was adequate because potassium and aldosterone levels in all patients had returned to their basal before 
Table 2 Participants' characteristics and values for selected variables before the first allocation

\begin{tabular}{|c|c|c|c|}
\hline & $\begin{array}{c}\text { Olmesartan } \\
\quad(n=17)\end{array}$ & $\begin{array}{c}\text { Enalapril } \\
(n=13)\end{array}$ & $\begin{array}{c}\mathrm{P}- \\
\text { value }\end{array}$ \\
\hline Age, years & $60.2(12.9)$ & $59.9(11.6)$ & NS \\
\hline Female, $n(\%)$ & $8(47.1)$ & $2(15.4)$ & $<0.0001$ \\
\hline $\mathrm{BMI}, \mathrm{kg} / \mathrm{m}^{2}$ & $27.7(6.2)$ & $27.41(4.1)$ & NS \\
\hline Systolic blood pressure, mm Hg & $134.8(4.2)$ & $140.1(4.2)$ & NS \\
\hline Diastolic blood pressure, $\mathrm{mm} \mathrm{Hg}$ & $78.7(1.7)$ & $76.2(1.8)$ & NS \\
\hline Dyslipidaemia, n (\%) & $6(35.3)$ & $5(38.5)$ & NS \\
\hline Serum creatinine, mg/dl & $1.65(0.07)$ & $1.60(0.06)$ & NS \\
\hline $\begin{array}{l}\text { Glomerular filtration rate, } \\
\mathrm{ml} / \mathrm{min} / 1.73 \mathrm{~m}^{2}\end{array}$ & $42.24(2.0)$ & $46.2(1.9)$ & NS \\
\hline Plasma renin activity, $\mathrm{ng} / \mathrm{ml} / \mathrm{h}$ & $1.13(1.12)$ & $1.30(1.46)$ & NS \\
\hline Plasma aldosterone, ng/dl & $30.6(4.0)$ & $27.1(5.5)$ & NS \\
\hline Diabetic patients, $n(\%)$ & $1(5,8)$ & $2(15)$ & NS \\
\hline
\end{tabular}

BMI: Body mass index, NS: no significant.

Values are expressed as mean \pm SE of the mean.

beginning the second phase. During the second period, $42 \%$ of patients in the enalapril group developed hyperkalemia, and thus were withdrawn from the study at weeks $4(n=1)$ and $8(n=2)$. A similar percentage of those treated with olmesartan also developed kyperkalemia at the same time-points. Therefore, 27 patients fully participated in the olmesartan arm and 20 in the enalapril arm, resulting in unbalanced groups that prevented inferences with respect to secondary outcomes and further analysis of association between the presence of hyperkalemia and other measured variables. Mild adverse effects were reported in both groups, $\mathrm{n}=16$ for olmesartan and $\mathrm{n}=10$ for enalapril. We had two diabetic patients in the enalapril group and one in the olmesartan group (Table 2). One out of three of the diabetic patients included in the study showed raised potassium levels with both drugs. Two patients showed hyperkalemia with olmesartan and not with enalapril and likewise 2 patients showed hyperkalemia with enalapril and not with olmesartan.

Of note, there was no significant increase in serum potassium with either olmesartan or enalapril in 50\% of patients. There were no significant differences in the percentage of patients with hyperkalemia with respect to the treatment group (37\% for olmesartan and $40 \%$ for enalapril). However, there was a significant $(\mathrm{p}<0.05)$ and immediate (1 week) increase in serum potassium levels with respect to baseline values in both treatments; $10.5 \%$ for olmesartan (from $4.35 \pm 0.05$ to $4.59 \pm 0.05 \mathrm{mmol} / \mathrm{L}$ ) and $10.7 \%$ for enalapril (from $4.30 \pm 0.06$ to $4.60 \pm$ $0.09 \mathrm{mmol} / \mathrm{L}$ ) (Figure 2). This trend only remained significant during the first 8 weeks. Olmesartan patients showed potassium levels of up to $5.1 \mathrm{mmol} / \mathrm{L}: 2$ patients in week 1, up to $6.5 \mathrm{mmol} / \mathrm{L}$ : 2 patients in week 4 and up to $5.1 \mathrm{mmol} / \mathrm{L}$ : 1 patient in week 8 . Patients treated with

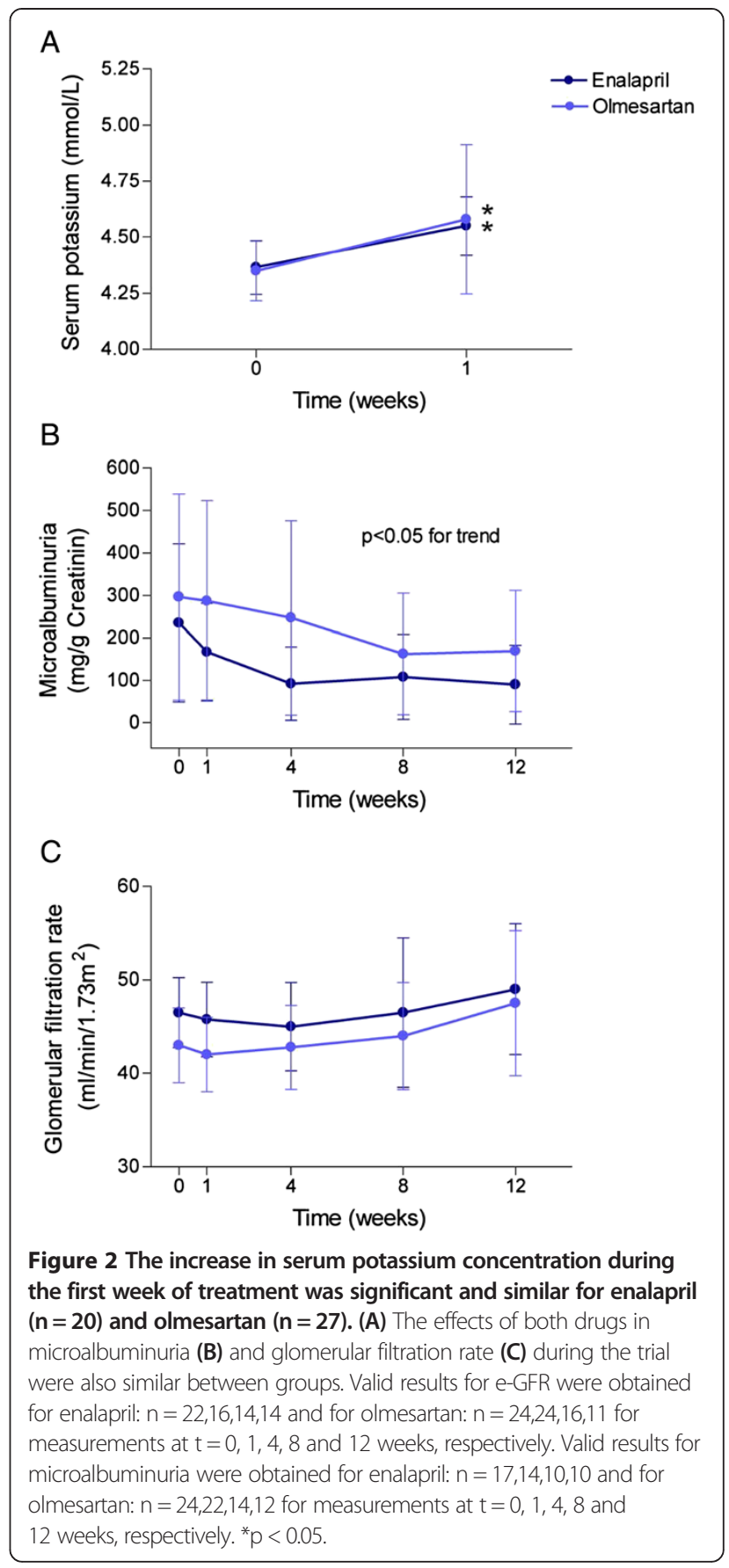

enalapril showed potassium levels of up to $5.5 \mathrm{mmol} / \mathrm{L}$ : 1 patient in week 1 , up to $5.4 \mathrm{mmol} / \mathrm{L}: 1$ patient in week 4 and up to $5.2 \mathrm{mmol} / \mathrm{L}: 2$ patients in week 8 .

That is to say, up to week 8,3 out of $30(10 \%)$ patients who were treated with these drugs did not show potassium levels over $5 \mathrm{mmol} / \mathrm{L}$. Only two patients, one in each treatment group, reached potassium levels above $5.5 \mathrm{mmol} / \mathrm{L}$, and the highest figure was $6,4 \mathrm{mmol} / \mathrm{L}$ in a diabetic patient. 
In enalapril treated patients baseline systolic BP was of $135.78 \pm 16 \mathrm{mmHg}$ and of $124 \pm 13 \mathrm{mmHg}$ at the end $\mathrm{p}<0.05$, baseline diastolic BP was $79.7 \pm 6.8 \mathrm{mmHg}$ and $74 \pm 10 \mathrm{mmHg}$ at the end $\mathrm{p}=0.09$. In olmesartan treated patients baseline systolic BP was $136.33 \pm 17.9 \mathrm{mmHg}$ and $131.13 \pm 13 \mathrm{mmHg}$ at the end $\mathrm{p}=0.4$, diastolic baseline $\mathrm{BP}$ was $79 \pm 7 \mathrm{mmHg}$ and $78 \pm 9$ at the end $\mathrm{p}=0.7$. It is true that the drop in systolic BP was significant in enalapril patients with regards to baseline, however the differences were not significative when we compared the systolic and diastolic BP at baseline between olmesartan and enalapril patients and systolic and diastolic BP at the end of the study.

In that sense we should say that our objective was not $\mathrm{BP}$ control but to maintain the ACEI/ARB doses in order to perform strict evaluation of potassium levels. The patients were receiving different doses of doxazosine or calcium-channel-blockers at baseline and in many cases their BP was already treated and controlled before beginning the trial. If the patient required a drug to lower BP we did this with different doses of doxazosine or calciumchannel-blockers. Therefore, we believe that it is not possible to draw conclusions on BP evolution.

Furthermore, among those terminating the study there were no significant differences in urinary potassium with respect to baseline values $(79.6 \pm 9.4$ vs. $81.1 \pm 8.1 \mathrm{mmol} / \mathrm{L}$ for olmesartan and $81.7 \pm 15.2$ vs. $62.7 \pm 6.5 \mathrm{mmol} / \mathrm{L}$ for enalapril) or appreciable changes in daily urine sodium elimination. Similar trends were observed for the transtubular potassium gradient $(6.7 \pm 0.4$ vs. $6.75 \pm 0.5$ for olmesartan and $6.8 \pm 0.6$ vs. $6.21 \pm 0.7$ for enalapril). The baseline serum osmolarity was within normal levels. At 12 weeks we observed a trend towards higher plasma renin activity in both arms that did not reach statistical significance $(1.13 \pm 1.12$ vs. $1.56 \pm 1.77$ and $1.30 \pm 1.46$ vs. $1.61 \pm 1.83 \mathrm{ng} / \mathrm{ml} / \mathrm{h}$ for olmesartan and enalapril respectively) and lower plasma aldosterone that was only significant $(\mathrm{p}<0.05)$ for enalapril $(27.6 \pm 3.8 \mathrm{vs.} 18.7 \pm 2.9 \mathrm{ng} / \mathrm{dl})$.

Microalbuminuria, which was tested as a urine spot: $\mathrm{mg}$ albumin/gr creatinine ratio, was $278 \pm 134$ and $151 \pm 119$ at baseline for olmesartan and enalapril patients respectively, which had diminished to $213 \pm 90$ and $106 \pm 59$ respectively (Figure 2) at the end of the $4^{\text {th }}$ week. That represents an overall decrease in microalbuminuria concentrations of $23 \%$ and $29 \%$ for the olmesartan and enalapril groups respectively. This decrease only reached statistical significance when compared with ANOVA indicating a detectable trend towards a positive effect. We found no further decrease of microalbuminuria in the following controls (Figure 2).

Finally, baseline eGFR of olmesartan patients went from $46.3 \pm 3.7$ to $48.59 \pm 4.3 \mathrm{ml} / \mathrm{mint} / 1.73 \mathrm{~m}^{2}$ at the end, and the baseline eGFR of enalapril patients went from $46.8 \pm$ 3.1 to $48.3 \pm 4.3 \mathrm{ml} / \mathrm{mint} / 1.73 \mathrm{~m}^{2}$ at the end. The e-GFR underwent a slight decrease in the first weeks, recovering at the end of the study (Figure 2).

\section{Discussion}

Sudden cardiac arrest and arrhythmia are prominent causes of death among patients with chronic kidney disease and in most cases the patient's potassium level is associated with the risk of death [35]. Therefore, it is clinically advisable to carefully monitor these patients, to ensure proper dietary management and to avoid potentially deleterious drugs. According to our data, in this CKD stage 3 group, olmesartan and enalapril increased potassium levels at a mean of $0.3 \mathrm{mmol} / \mathrm{L}$, which was greater than $5 \mathrm{mmol} / \mathrm{L}$ in $40 \%$ of patients. The clinical implications are relevant because potassium levels require continuous surveillance and because these drugs are effective in retarding the progression of renal disease, especially when this is moderate and requires strict control of blood pressure [36]. A possible clinical difference between ACEIs and ARBs in terms of their effect on serum potassium was initially described [7,24,28], but modifications to drugs in these categories are continuously being incorporated into the therapeutic armamentarium, with possible, unexplored effects. A common problem is that trials do not appreciate the effect of stringent criteria for withdrawal and the strict control of confounding factors $[8,12,16]$. There has been no previous clinical study comparing olmesartan and enalapril in stage 3 CKD patients. We continuously controlled sodium and potassium intake and excretion in order to limit possible changes in serum potassium levels to those due to the presence of the drugs assayed. We found no significant differences between olmesartan and enalapril in their capacity to cause hyperkalemia in patients with e-GFR $>30$ and $<60 \mathrm{ml} /$ $\min / 1.73 \mathrm{~m}^{2}$ but confirmed that both drugs influence the potassium balance $[7,26]$, decrease urinary albumin excretion by $25 \%$ at 1 month and maintain renal function. Additionally, we found that we should not expect changes in serum potassium levels due to these drugs in approximately half of patients with CKD in whom diet is controlled. As previously suggested this may be partially attributed to the unequal distribution of polymorphisms in the angiotensin-converting enzyme gene [37].

Differences between ACEIs and ARBs, however, were initially plausible considering their differential effect on the bradikinine metabolism and plasmatic renal flow $[22,23]$. Our findings of lower plasma aldosterone and greater anti-hypertensive effects with enalapril provide further support for such differences. There were no differential effects on serum potassium level in uncontrolled patients with normal renal function, as demonstrated in a comparison between lisinopril and candesartan [38]. Only one study exists, also well designed, which compared $80 \mathrm{mg}$ of Valsartan with $10 \mathrm{mg}$ of lisinopril in 18 stage 3 
CKD patients and found that valsartan produces less hyperkalemia. The explanation could lie in the different half lives of these drugs (12 hours for lisinopril and 6 hours for valsartan) [39], which could mean valsartan had less effect on potassium levels. In this study there is no reference to the potassium intake [7].

There are no data to support a difference in potency between olmesartan and enalapril; they have similar half lives (11 hours for enalapril and 12 hours for olmesartan) [39] and animal models indicate that olmesartan and enalapril are equivalent [40]. Moreover, studies comparing ACEIs and ARBs have yielded similar results [36,41]. No differences have been reported between ACEIs [42], but olmesartan has been reported as the most potent ARB to date $[43,44]$.

We were particularly careful to avoid differences in dietary potassium intake. We are aware that assessment may be biased by the type of ingestion and the methods of recall [45] and consequently we included continuous laboratory measurement of electrolyte balance. Lack of adherence was limited but caused some withdrawals. The intake of potassium in a free-diet varies between 42 and $270 \mathrm{mmol} /$ day. Our restrictions resulted in similar individual daily urinary potassium and sodium excretion and no relevant differences between drugs, supporting our conclusion that $20 \mathrm{mg}$ of olmesartan does not produce more hyperkalemia than $20 \mathrm{mg}$ of enalapril in stage 3 CKD patients. It is difficult to know if these results can be attributed to the entire pharmacological class or specifically to these two drugs.

In fact both drugs increased serum potassium levels. This increase was not particularly high due to our selection criteria and exhaustive control but values higher than $5 \mathrm{mmol} / \mathrm{L}$ were found in $30-40 \%$ of patients studied, indicating a frequent concern at this stage that is probably more important in patients with more severe CKD and in patients with dual blockade of the renin-angiotensin system [4]. Clinicians should consider that in daily clinical practice, in the "real world", patients are usually influenced by a free potassium diet and established or temporary conditions that may aggravate hyperkalemia. Hence the effect of prescribed drugs should be monitored frequently. If treatment is not readily withdrawn, as described previously [12], the incidence of severe hyperkalemia may increase, notably within the first year of treatment. This is particularly relevant as severe hyperkalemia is found in $1 \%$ of ambulatory patients and most with suboptimal followup and management; very moderate increases in serum potassium may also generate arrhythmia [10,46]. We also wish to underline that having "slightly" and sustained, higher levels of potassium, not affecting the electrical cardiac conduction, could cause other unknown effects in the long term. On the other hand, we believe that these drugs should be utilized when indicated, if well managed (diuretics, diet, etc.) to maintain adequate potassium levels. Bearing in mind that some patients showed hyperkalemia with one drug and not with the other, we believe that in those patients with indispensable indication, for example, heavy proteinuria, we could try the alternative drug.

It is well documented that CKD patients in whom treatment with ACEIs or ABRs is indicated should be frequently checked for serum potassium levels. The most usual recommendations indicate that this should be done 7-10 days after prescription [10].

Nevertheless, in the light of our results we believe that stage 3 CKD patients treated with these drugs should also be controlled at the end of month 1 and 2; After that point, patients should be controlled at the periods recommended at guidelines, to follow-up stable stage 3 CKD patients, and also when a concomitant disease appears. Whether this is a cost-effective recommendation remains to be ascertained.

\section{Conclusions}

In conclusion, patients with stage 3 CKD are prone to disturbances in potassium balance upon treatment with either olmesartan or enalapril. Hyperkalemia was present in a significant number of patients and there were no relevant differences between drugs. The follow-up of these patients should include frequent measurement of potassium levels at least during the first 2 months of treatment.

\section{Abbreviations}

ACEl: Angiotensin-converting enzyme inhibitors; ARB: Angiotensin receptor blocker; GFR: Glomerular filtration rate; CKD: Chronic kidney disease; e-GFR: Estimated-GFR; BP: Blood pressure.

\section{Competing interests}

The authors declare that they have no competing interests.

\section{Authors' contributions}

EE conceived the study, and participated in its design, interpretation of data and coordination and helped to draft the manuscript. JJ was involved in interpretation of data and also helped to draft the manuscript. IG

participated in coordination and interpretation of data. PS participated in the design of the study and performed the statistical analysis. BR took part in the sequence of randomization and participated in the design. JF participated in coordination and revising the manuscript for intellectual content. DS

collaborated with revising the manuscript for intellectual content. All authors read and approved the final manuscript.

\section{Acknowledgements}

The authors wish to thank Dr. Sonia Caparrós Molina and Dr. Bruno Montoro for technical assistance and useful discussion of the data. The work of the authors is supported by a grant from The Spanish Ministry of Health and Social Policy, project TRA-197, and an unrestricted grant from Pfizer, Spain. The Spanish Agency for medicines and medical products provided support and authorized the trial EudraCT "2008-002191-98".

\section{Author details}

${ }^{1}$ Servei de Nefrologia, Hospital Vall d'Hebron, Universitat Autònoma, Barcelona, Spain. ${ }^{2}$ Unitat de Recerca Biomèdica (URB-CRB), Institut d'Investigació Sanitària Pere Virgili, Universitat Rovira i Virgili, Reus, Spain. ${ }^{3}$ Servei de Farmacia, Hospital Vall d'Hebron, Universitat Autònoma, Barcelona, Spain. 
Received: 28 December 2012 Accepted: 29 July 2013

Published: 1 August 2013

\section{References}

1. Stevens MS, Dunlay RW: Hyperkalemia in hospitalized patients. Int Urol Nephrol 2000, 32:177-180.

2. Jarman PR, Kehely AM, Mather HM: Hyperkalaemia in diabetes: prevalence and associations. Postgrad Med J 1995, 71:551-552.

3. Ponce SP, Jennings AE, Madias NE, Harrington JT: Drug-induced hyperkalemia. Med (Baltimore) 1985, 64:357-370

4. Mogensen CE, Neldam S, Tikkanen I, Oren S, Viskoper R, Watts RW, Cooper ME: Randomised controlled trial of dual blockade of renin-angiotensin system in patients with hypertension, microalbuminuria, and non-insulin dependent diabetes. BMJ 2000, 321:1440-1444.

5. De Denus S, Tardif JC, White M, Bourassa MG, Racine N, Levesque S, Ducharme A: Quantification of the risk and predictors of hyperkalemia in patients with left ventricular dysfunction: a retrospective analysis of the studies of left ventricular dysfunction (SOLVD) trials. Am Heart J 2006, 152:705-712.

6. Korgaonkar S, Tilea A, Gillespie BW, Kiser M, Eisele G, Finkelstein F, Kotanko $P$, Pitt B, Saran R: Serum potassium and outcomes in CKD: insights from the RRI-CKD cohort study. Clin J Am Nephrol 2010, 5:762-769.

7. Bakris GL, Siomos M, Richardson D, Janssen I, Bolton WK, Hebert L, Agarwal R, Catanzaro D: ACE inhibition or angiotensin receptor blockade: impact on potassium in renal failure. Kidney Int 2000, 58:2084-2092.

8. Takaichi K, Takemoto F, Ubara Y, Mori Y: Analysis of factors causing hyperkalemia. Intern Med 2007, 46:823-829.

9. El-Sherif N, Turitto G: Electrolyte disorders and arrhythmogenesis. Cardiol J $2011,18: 233-245$

10. Mount DB, Kambiz ZN: Disorders of potassium balance. In Brenner \& Rector's the kidney. Volume 1. 9th edition. Edited by Taal MV, Chertow GM, Marsden PA, et al. Philadelphia, USA: Elsevier Saunders; 2012:640-678.

11. Palmer BF: Managing hyperkalemia caused by inhibitors of the reninangiotensin-aldosterone system. N Engl J Med 2004, 351:585-592.

12. Reardon LC, Macpherson DS: Hyperkalemia in outpatients using angiotensin-converting enzyme inhibitors. How much should we worry? Arch Intern Med 1998, 158:26-32.

13. Mancia G, De Backer G, Dominiczak A, Cifkova R, Fagard R, Germano G, Grassi G, Heagerty AM, Kjeldsen SE, Laurent S, Narkiewicz K, Ruilope L, Rynkiewicz A, Schmieder RE, Boudier HA, Zanchetti A, Vahanian A, Camm J, De Caterina R, Dean V, Dickstein K, Filippatos G, Funck-Brentano C Hellemans I, Kristensen SD, McGregor K, Sechtem U, Silber S, Tendera M, Widimsky $P$, et al: Guidelines for the management of arterial hypertension. The task force for the management of arterial hypertension of the European society of hypertension and of the European society of cardiology. J Hipertens 2007, 25:1105-1187.

14. Palmer BF: Angiotensin-converting enzyme inhibitors and angiotensin receptor blockers: what to do if serum creatinine and/or serum potassium concentration rises. Nephrol Dial Trans 2003, 18:1973-1975.

15. Hunt SA: ACC/AHA 2005 guidelines update for the diagnosis and management of chronic heart failure in the adult. J Am Coll Cardiol 2005, 46:e1-e82.

16. Maschio G, Alberti D, Janin G, Locatelli F, Mann JF, Motolese M, Ponticelli C, Ritz E, Zucchelli P: Effect of angiotensin-converting-enzime inhibitor benazepril on the progression of chronic renal insufficiency. N Engl J Med 1996, 334:939-945

17. Lewis EJ, Hunsicker LG, Bain RP, Rohde RD: The effect of angiotensinconverting-enzyme inhibition on diabetic nephropathy. N Engl J Med 1993, 329:1456-1462.

18. Parving HH, Lehnert H, Bröchner-Mortensen J, Gomis R, Andersen S, Arner PJ: The effect of irbesartan on development of diabetic nephropathy in patients with type 2 diabetes. N Engl J Med 2001, 345:870-878.

19. Lewis EJ, Hunsicker LG, Clarke WR, Berl T, Pohl MA, Lewis JB, Ritz E, Atkins $R C$, Rohde R, Raz I: Renoprotective effect of the angiotensin-receptor antagonist irbesartan in patients with nephropathy due to type 2 diabetes. N Engl J Med 2001, 345:851-860.

20. Brenner BM, Cooper ME, De Z, Keane WF D, Mitch WE, Parving HH, Remuzzi G, Snapinn SM, Zhang Z, Shahinfar S: Effects of losartan on renal and cardiovascular outcomes in patients with type 2 diabetes and nephropathy. N Engl J Med 2001, 345:861-869.
21. Jafar TH, Stark PC, Schmid CH, Landa M, Maschio G, de Jong PE, de Zeeuw D, Shahinfar S, Toto R, Levey AS: Progression of chronic kidney disease: the role of blood pressure control, proteinuria, and angiotensinconverting enzyme inhibition: a patient-level meta-analysis. Ann Intern Med 2003, 139:244-252.

22. Weir MR, Rolfe M: Potassium homeostasis and renin-angiotensin-aldosterone system inhibitors. Clin J Am Soc Nephrol 2010, 5:531-548.

23. Weir MR: Are drugs that block the renin-angiotensin system effective and safe in patients with renal insufficiency? Am J Hypertens 1999, 12:195S-203S.

24. Mckelvie RS, Yusuf S, Pericak D, Avezum A, Burns RJ, Probstfield J, Tsuyuki RT, White M, Rouleau J, Latini R, Maggioni A, Young J, Pogue J: Comparison of candesartan, enalapril, and their combination in congestive heart failure: randomized evaluation of strategies for left ventricular dysfunction (RESOLVD) pilot study. Circulation 1999, 100:1056-1064.

25. Gansevoort RT, de Zeeuw D, Shahinfar S, Redfield A, de Jong PE: Effects of the angiotensin II antagonist losartan in hypertensive patients with renal disease. J Hypertens supp/ 1994, 12(suppl 2):37-42.

26. Kuriyama S, Tomonari H, Tokudome G, Horiguchi M, Hayashi H, Kobayashi $\mathrm{H}$, Ishikawa M, Hosoya T: Antiproteinuric effects of combined antihypertensive therapies in patients with overt type 2 diabetic nephropathy. Hypertens Res 2002, 25:849-855.

27. Hou FF, Zhang $X$, Zhang GH, Xie D, Chen PY, Zhang WR, Jiang JP, Liang M, Wang GB, Liu ZR, Geng RW: Efficacy and safety of benazapril for advanced chronic renal insufficiency. N Engl J Med 2006, 354:131-140.

28. Pitt B, Segal R, Martinez FA, Meurers G, Cowley AJ, Thomas I, Deedwania PC, Ney DE, Snavely DB, Chang PI: Randomised trial of losartan versus captopril in patients over 65 with heart failure (Evaluation of Losartan in the Elderly Study, ELITE). Lancet 1997, 349:747-752.

29. Rastegar A, Soleimani M: Hipokalaemia and hyperkalaemia. Postgrad Med J 2001, 77:759-764.

30. Levey AS, Bosch JP, Lewis JB, Greene T, Rogers N, Roth D: A more accurate method to estimate glomerular filtration rate from serum creatinine: a new prediction equation. Modification of diet in renal disease study group. Ann Intern Med 1999, 130:461-470.

31. Morisky DE, Green LW, Levine DM: Concurrent and predictive validity of a self-reported measure of medication adherence. Med Care 1986, 24:67-74.

32. Svarstad BL, Chewning BA, Sleath BL, Claesson C: The brief medication questionnaire: a tool for screening patient adherence and barriers to adherence. Patient Educ Couns 1999, 37:113-124.

33. Yasky J, Verho M, Erasmus TP, Luus HG, Angela M, Grandin L, Akbary MA, Rangoonwala B: Efficacy of ramipril versus enalapril in patients with mild to moderate essential hypertension. Br J Clin Pract 1996, 50:302-310.

34. Omboni S, Malacco E, Mallion JM, Volpe M: Antihypertensive efficacy and safety of olmesartan medoxomil and ramipril in elderly mild to moderate essential hypertensive patients with or without metabolic syndrome: a pooled post hoc analysis of two comparative trials. Drugs Aging 2012, 29:981-992.

35. Pun PH, Herzog CA, Middleton JP: Improving ascertainment of sudden cardiac death in patients with end stage renal disease. Clin J Am SoC Nephrol 2012, 7:116-122.

36. Sharma P, Blackburn RC, Parke CL, McCullough K, Marks A, Black C: Angiotensin-converting enzyme inhibitors and angiotensin receptor blockers for adults with early (stage 1 to 3) non diabetic chronic kidney disease. Cochrane Database Syst Rev 2011, 10:CD007751.

37. Espinel E, Tovar JL, Borrellas J, Piera L, Jardi R, Frias FR, Armadans L, Bachs $A G J$ : Angiotensin-converting enzyme i/d polymorphism in patients with malignant hypertension. J Clin Hypertens (Greenwich) 2005, 7:11-15.

38. Preston RA, Baltodano NM, Alonso AB, Epstein M: Comparative effects on dynamic renal potassium excretion of $A C E$ inhibition versus angiotensin receptor blockade in hypertensive patients with type II diabetes mellitus. J Clin Pharmacol 2002, 42:754-757.

39. Sanders GD, Coeytaux R, Dolor RJ, Hasselblad V, Patel UD, Powers B, Gray RN, Irvine RJ, Kendrick A: Angiotensin-converting enzyme inhibitors (ACEls), angiotensin II receptor antagonists (ARBs), and direct renin inhibitors for treating essential hypertension: an update. Rockville (MD): Agency for Healthcare Research and Quality (US), AHRQ Comparative Effectiveness Reviews; 2011. 11-EHC063-EF.

40. Porteri E, Rodella L, Rizzoni D, Rezzani R, Paiardi S, Sleiman I, De Ciuceis C, Boari GE, Castellano M, Bianchi R, Agabiti-Rosei E: Effects of olmesartan and 
enalapril at low or high doses on cardiac, renal and vascular interstitial matrix in spontaneously hypertensive rats. Blood Press 2005, 14:184-192.

41. Mimran A, Ruilope L, Kerwin L, Nys M, Owens D, Kassler-Taub K, Osbakken M: A randomized, double-blind comparison of the angiotensin II receptor antagonist, irbesartan, with the full dose range of enalapril for the treatment of mild to moderate hypertension. J Hum Hypertens 1998 , 12:203-208

42. Heran BS, Wong MM, Heran IK, Wright JM: Blood pressure lowering efficacy of angiotensin converting enzyme (ACE) inhibitors for primary hypertension. Cochrane Database Syst Rev 2008, 4, CD003823.

43. Oparil S, Williams D, Chrysant SG, Marbury TC, Neutel J: Comparative efficacy of olmesartan, losartan, valsartan and irbesartan in the control of essential hypertension. J Clin Hypertens (Greenwich) 2001, 3:283-291.

44. Fabia MJ, Abdilla N, Oltra R, Fernandez C, Redon J: Antihypertensive activity of angiotensin II AT1 receptor antagonists: a systematic review of studies with $24 \mathrm{~h}$ ambulatory blood pressure monitoring. J Hypertens 2007, 25:1327-1336.

45. Crispim SP, Geelen A, Siebelink E, Huybrechts I, Lillegaard IT, Margaritis I, Rehurkova I, Slimani N, Ocke MC, de Boer E, van't Veer P, de Vries JH: Design aspects of $24 \mathrm{~h}$ recall assessments may affect the estimates of protein and potassium intake in dietary surveys. Public Health Nutr 2012 15:1196-2000

46. Moore CR, Lin JJ, O'Connor N, Halm EA: Follow-up of markedly elevated serum potassium results in the ambulatory setting: implications for patient safety. Am J Med Qual 2006, 21:115-124.

doi:10.1186/1756-0500-6-306

Cite this article as: Espinel et al:: Risk of hyperkalemia in patients with moderate chronic kidney disease initiating angiotensin converting enzyme inhibitors or angiotensin receptor blockers: a randomized study. BMC Research Notes 2013 6:306.

\section{Submit your next manuscript to BioMed Central and take full advantage of:}

- Convenient online submission

- Thorough peer review

- No space constraints or color figure charges

- Immediate publication on acceptance

- Inclusion in PubMed, CAS, Scopus and Google Scholar

- Research which is freely available for redistribution 